\title{
PENGARUH METODE DAN MEDIA PEMBELAJARAN TERHADAP HASIL BELAJAR BAHASA INDONESIA
}

\author{
Muhamad Yasir \\ Program Studi Teknik Industri \\ FTMIPA Universitas Indraprasta PGRI \\ kangyassir@gmail.com
}

\begin{abstract}
Abstrak
Penelitian ini bertujuan untuk mengetahui pengaruh Metode Pembelajaran terhadap hasil belajar bahasa Indonesia dan mengetahui pengaruh Media Pembelajaran terhadap hasil belajar bahasa Indonesia, serta untuk mengetahui pengaruh Metode dan Media Pembelajaran terhadap hasil belajar bahasa Indonesia. Metode yang digunakan dalam penelitian ini adalah metode Eksperimen. Populasi terjangkau adalah siswa SMP Swasta kota Bekasi. Besar sample sebanyak 80 siswa, dengan teknik random sampling yang dibagi ke dalam empat kelas penelitian. Instrumen penelitian yang digunakan yaitu tes hasil belajar bahasa Indonesia berbentuk pilihan ganda sebanyak 30 soal yang telah di uji validitasnya dengan koefisien realibilitas $=0,05$ analisis data menggunakan analysis of varians (ANAVA) dua arah; perlakuan menggunakan metode Inkuiri dan Media Audio Visual. Hasil pengujian hipotesis diperoleh simpulan sebagai berikut: 1) Terdapat pengaruh yang signifikan metode pembelajaran terhadap hasil belajar bahasa Indonesia hal tersebut dibuktikan dengan Fh 29.644 dan sig. sebesar 0,000 < 0,05,2) Terdapat pengaruh yang signifikan media pembelajaran terhadap hasil belajar bahasa Indonesia Hal tersebut dibuktikan dengan Fh 53.89 dan sig. $0,000<0,05,3)$. Terdapat pengaruh interaktif yang signifikan metode dan media pembelajaran terhadap hasil belajar bahasa Indonesia hal tersebut dibuktikan dengan $\mathrm{Fh} 5.705$ dan sig. $0,019<0,05$.
\end{abstract}

Kata Kunci : Metode Pembelajaran, Media Pembelajaran, Hasil Belajar Bahasa Indonesia

\begin{abstract}
The purpose of this research is to know the effects of learning method and teaching aid toward Indonesian subject achievement. The method used in the study was experiment. Population of the research is the students of private school in Bekasi with the total sampel 80 students by using random sampling technique which was divided into four classes. The instrument was the Indonesian subject achievement was a multiple choice test around 30 questions which validity test by realibity coefficient $=0.05$. In this research,the reseacher used analysis of two ways varians (ANAVA) to analize the data. The method used was Inquiry and media was audio visual. The result of test hypoteses are :1) there was a significant effect of using the inquiry method toward Indonesian subject achievement. This proven by Ftest 20,644 by sig. 0,000 $<0.05$. 2) There was a significant effect of using audio visual teaching teaching aids. This proven by Fh 53.89 and sig. $0.000<0.05 .3)$ There was a significant interactive effect between the usage of inquiry method and audio visual teaching aids towards the Indonesian subject achievement. This proven by Fh.5.705 and sig. $0.019<0.05$.
\end{abstract}

Key words: Learning Method, Teaching Aid, The Indonesian Subject achievement.

\section{PENDAHULUAN}

Dunia pendidikan adalah dunia yang sangat penting dalam kehidupan manusia. Manusia yang selalu diiringi pendidikan, kehidupannya akan selalu berkembang ke arah yang lebih baik. Tidak ada zaman yang tidak berkembang, tidak ada kehidupan manusia yang tidak bergerak, dan tidak ada manusia pun yang hidup dalam stagnasi peradaban. Semuanya itu bermuara pada 
pendidikan, karena pendidikan adalah pencetak peradaban manusia.

Dengan adanya perkembangan kehidupan, pendidikan pun mengalami dinamika yang semakin lama semakin berkembang dan berusaha beradaptasi dengan gerak perkembangan yang dinamis tersebut. Itulah sebabnya, pendidikan yang kini diterapkan kepada peserta didik kita tidak sama dengan pendidikan kita sewaktu sekolah dulu. Setiap zaman, pasti akan selalu ada perubahan yang mengarah pada kemajuan pendidikan yang semakin baik.

Di samping itu, pendidikan juga memerlukan berbagai inovasi. Hal ini penting dilakukan untuk kemajuan kualitas pendidikan yang tidak hanya menekankan pada teori, tetapi harus bisa diarahkan pada hal yang bersifat praktis. Diakui atau tidak, walaupun belum ada penelitian khusus tentang pembelajaran, banyak yang merasa bahwa sistem pendidikan, terutama pada proses belajarmengajar, terasa sangat membosankan.

Berdasarkan pengamatan penulis, fenomena yang terjadi pada peserta didik saat ini, dimana mereka menganggap bahwa aktivitas yang mengasyikan justru berada di luar jam pelajaran. Hal ini dikarenakan selama ini mereka merasa terbebani ketika berada di dalam kelas, apalagi jika harus mengahadapi mata pelajaran tertentu yang membosankan. Mereka akan bersorak-sorai jika mendengar pengumunan pulang lebih cepat karena ada rapat guru, pembatalan ulangan, atau guru tidak mengajar karena sakit, dan lain sebagainya.

Maka dari itu, kita membutuhkan inovasi pembelajaran agar peserta didik menjadi bersemangat, mempunyai motivasi untuk belajar, dan antusias menyambut pelajaran disekolah. Jika mereka senang saat memasuki kelas maka mereka pasti akan mudah dalam mengikuti mata pelajaran. Hal ini dapat dijadikan terobosan yang patut dihargai dan diujicobakan.

Dalam pembelajaran bahasa Indonesia, tidak akan terlepas dari empat keterampilan berbahasa, yaitu menyimak, berbicara, membaca dan menulis. Kemampuan berbahasa bagi manusia sangat diperlukan. Sebagai makhluk sosial, manusia berinteraksi, berkomunikasi dengan manusia lain dengan menggunakan bahasa sebagai media, baik berkomunikasi menggunakan bahasa lisan, juga berkomunikasi menggunakan bahasa tulis.

Pembelajaran bahasa Indonesia yang efektif, menyenangkan, menarik, dan bermakna bagi peserta didik dipengaruhi oleh berbagai unsur, antara lain guru yang memahami secara utuh hakikat, sifat, dan karakteristik peserta didik. Metode pembelajaran yang berpusat pada kegiatan peserta didik, sarana belajar anak yang memadai, tersedianya sumber belajar yang menarik dan mendorong peserta didik untuk belajar, dan lain-lain. Hal ini tentu saja menuntut aktivitas kreativitas guru dalam menciptakan lingkungan yang kondusif. Menurut Mulyasa dalam (Susanto, 2013:50) proses penyampaian materi atau proses pembentukan kompetensi dikatakan efektif apabila seluruh peserta didik terlibat secara aktif, baik mental, fisik, maupun sosialnya.

Kegiatan pembelajaran yang optimal dalam proses pembelajaran ini sedikitnya mencakup lima aspek, yaitu: 1) penyampaian tujuan pembelajaran; 2 ) penyampaian materi atau bahan ajar dengan memperhatikan pendekatan, metode, sarana, dan alat atau media yang tepat; 3) pemberian bimbingan bagi siswa; 4) melakukan pemeriksaan atau pengecekkan mengenai pemahaman siswa, dan 5) tentang pengelolaan kelas.

Mengajar yang berhasil menuntut penggunaan metode belajar yang tepat. Setiap guru tentu mempunyai metode, 
dan seorang guru yang baik akan memahami dengan baik metode yang akan digunakannya. Pandangan yang sering dikemukakan adalah bahwa tidak ada satu metode pun yang baik untuk semua mata pelajaran. Maka, atas alasan inilah setiap guru dituntut untuk mampu memilih dan menggunakan metode yang tepat dalam melaksanakan pembelajaran. Metode mengajar ini digunakan guru dalam mengorganisasikan kelas pada umumnya atau dalam menyajikan bahan pelajaran pada khususnya. Metode diperlukan dalam rangka untuk mencapai tujuan pembelajaran, dimana dengan metode tersebut dapat memudahkan siswa menerima dan memahami materi pelajaran yang diberikan oleh guru.

Mengingat peran media belajar sangat penting dalam menunjang keberhasilan penciptaan proses dan pencapaian hasil belajar yang diharapkan, maka pemahaman guru secara utuh mengenai pentingnya media belajar merupakan salah satu aspek yang harus menjadi perhatian guru. Peran media belajar adalah bagian yang tidak terpisahkan dalam proses pembelajaran. Seorang guru yang baik akan memahami, menggunakan, dan memanfaatkan media belajar dengan baik dan tepat. Melalui media ini dapat mempermudah dalam memahami materi-materi yang diberikan oleh guru, karena media akan membantu peserta didik untuk memvisualkan hal-hal abstrak, mengasah rasa, merangsang kreativitas, menemukan pengetahuan, dan lain-lain.

Berdasarkan pembahasan tersebut dapat dipahami bahwa keberhasilan peserta didik dalam belajar tergantung pula pada metode dan model penyajian materi. Model penyajian materi yang menyenangkan, tidak membosankan, menarik, dan mudah dimengerti oleh peserta didik tentunya berpengaruh secara positif terhadap keberhasilan belajar. Penulis ingin melakukan sebuah penelitian dengan melakukan eksperimen pada SMP Swasta di kota Bekasi. Penulis ingin meneliti tentang pengaruh metode dan media pembelajaran terhadap hasil belajar bahasa Indonesia. Dengan demikian, dalam penelitian ini penulis memberi judul: "Pengaruh Metode dan Media Pembelajaran terhadap Hasil Belajar Bahasa Indonesia (Eksperimen pada SMP Swasta di kota Bekasi)".

Sedangkan R. Gagne seperti dikutip oleh Slameto memberikan dua definisi belajar, yaitu: belajar adalah suatu proses untuk memperoleh motivasi dalam pengetahuan, keterampilan, kebiasaan, dan tingkah laku, belajar adalah penguasaan pengetahuan atau keterampilan yang diperoleh dari intruksi (Slameto, 2003:13).

Menurut Indihadi (2006:57) dalam teori belajar dan pembelajaran, lima faktor yang harus dipadukan dalam berkomunikasi, sehingga pesan ini dapat disampaikan, yaitu: struktur pengetahuan, kebahasaan, strategi produktif, mekanisme psikofisik, dan konteks.

Pengertian di atas sejalan dengan arahan Badan Standar Nasional Pendidikan (BNSP, 2006: 81), bahwa standar isi bahasa Indonesia sebagai berikut: "pembelajaran bahasa Indonesia diarahkan untuk meningkatkan kemampuan peserta didik untuk berkomunikasi dalam bahasa Indonesia dengan baik dan benar, baik secara lisan maupun tulis, serta menumbuhkan apresiasi terhadap hasil karya kesastraan manusia Indonesia".

Berdasarkan pengertian di atas dapat disimpulkan bahwa pengajaran bahasa bertujuan untuk melatih keterampilan mendengar, berbicara, membaca, dan menulis yang masingmasing erat hubungannya. Pembelajaran bahasa Indonesia juga diarahkan untuk 
meningkatkan kemampuan peserta didik dalam berkomunikasi dengan bahasa Indonesia dengan baik dan benar baik secara lisan maupun tulisan, serta menumbuhkan pribadi yang mempunyai rasa apresiasi terhadap hasil karya sastra.

Pengertian hasil belajar dipertegas oleh Nawawi dalam K. Ibrahim (2007:39) yang menyatakan bahwa hasil belajar dapat diartikan sebagai tingkat keberhasilan siswa dalam mempelajari materi pelajaran di sekolah yang dinyatakan dalam skor yang diperoleh dari hasil tes mengenal sejumlah materi pelajaran tertentu.

Secara sederhana, yang dimaksud dengan hasil belajar adalah kemampuan peserta didik setelah melalui kegiatan belajar. Dalam kegiatan pembelajaran atau kegiatan intruksional, biasanya guru menetapkan tujuan belajar. Anak yang berhasil dalam belajar adalah peserta didik yang berhasil mencapai tujuantujuan pembelajaran. Menurut Moh. Amin (1987:12) peran guru dalam pembelajaran inkuiri adalah sebagai penyanya. Ia menjelaskan bahwa kemampuan peserta didik untuk setiap pertanyaan yang diajukan oleh guru merupakan sebagian dari proses berpikir. Kunci inkuiri adalah menanyakan atau mengajukan pertanyaan-pertanyaan yang signifikan.

Andi (2011: 70) mengatakan bahwa setidaknya ada dua macam bahan ajar audio visual, yakni video atau film dan orang. Untuk bahan ajar berbentuk video atau film, strukturnya meliputi enam komponen, yaitu judul, petunjuk belajar, kompetensi dasar atau materi pokok, informasi pendukung, latihan, dan penilaian. Sedangkan struktur bahan ajar orang hanya meliputi lima komponen. Itupun tidak semuanya terdapat pada bahan atau media orang (judul, kompetensi dasar, informasi pendukung) sedangkan komponen lain (latihan, dan penilaian) terdapat pada lembaran kertas yang lain.

\section{METODE PENELITIAN}

Pada penelitian ini menggunakan metode eksperimen, yaitu memberikan jenis perlakuan yang berbeda pada dua kelompok belajar siswa. Satu kelompok yang dijadikan kelompok eksperimen, yaitu kelompok yang diberikan perlakuan metode inkuri dan menggunakan media audio visual, sedangkan kelompok satu lagi disebut kelompok kontrol, yaitu kelompok dengan metode pembelajaran konvensional yang tidak menggunakan media belajar.

Dalam penelitian ini menggunakan metode eksperimen dengan desain faktorial 2 x 2 sebagai berikut:

Tabel 2. Desain Penelitian

\begin{tabular}{|c|c|c|c|}
\hline \multirow{2}{*}{$\begin{array}{c}\text { Media } \\
\text { Pembelajar } \\
\text { an }\end{array}$} & \multicolumn{2}{|c|}{$\begin{array}{c}\text { Metode } \\
\text { Pembelajaran } \\
\end{array}$} & \multirow{2}{*}{$\begin{array}{l}\text { Rata } \\
\text {-rata }\end{array}$} \\
\hline & $\begin{array}{c}\text { Inkui } \\
\text { ri }\end{array}$ & $\begin{array}{c}\text { Konvension } \\
\text { al }\end{array}$ & \\
\hline Audio visual & A1B1 & A2B1 & $\sum \mathrm{B} 1$ \\
\hline Buku teks & A1B2 & A2B2 & $\sum \mathrm{B} 2$ \\
\hline$\sum \mathbf{K}$ & $\sum \mathrm{K} 1$ & $\sum \mathrm{K} 2$ & \\
\hline
\end{tabular}

Populasi dalam penelitian ini adalah seluruh siswa SMPI Nurul Hikmah II kelas IX berjumlah 80 orang dan di SMP Al Falah berjumlah 80 orang. Dalam analisis deskriptif disajikan dalam bentuk rangkuman data ANAVA yang memuat mean dan standar deviasi dari setiap kelompok sampel. Sebelum dilakukan pengujian hipotesis, berdasarkan data-data yang terkumpul dari hasil penelitian ini terhadap datadata tersebut terlebih dahulu dilakukan uji persyaratan analisis data yaitu uji normalitas.

Uji normalitas pada penelitian ini adalah uji parametik dengan menggunakan uji liliefors. Uji normalitas dilakukan untuk mengetahui apakah data 
populasi berdistribusi normal atau tidak berdasarkan data sampel yang diperoleh.

Setelah uji normalitas terlihat indikasi data hasil penelitian berdistribusi normal, maka selanjutnya akan diuji homogenitas dari sampe penelitian. Uji Homogenitas dimaksudkan untuk menguji apakah data berasal dari populasi yang homogen atau tidak. Pada penelitian ini uji Homogenitas dilakukan dengan menggunakan uji Barlet.

Analisis data untuk pengujian hipotesis penelitian menggunakan Analysis Varians (ANAVA) dua jalur pada taraf signifikansi 5\%. Penelitian ini menggunakan metode eksperiment treatment by treatment, dengan dengan disain factorial 2x2, dengan memberikan perlakuan kepada kelompok eksperimen berupa kegiatan belajar mengajar dengan metode pembelajaran inkuiri dan penggunaan media audio visual. Dalam penelitian ini terdapat dua variable yang digunakan untuk dasar peninjauan untuk variable terikat.

\section{HASIL DAN PEMBAHASAN}

\section{HASIL PENELITIAN}

Setelah dilakukan uji normalitas dan homogenitas dan hasilnya menunjukkan bahwa sampel penelitian berasal dari populasi berdistribusi normal dan varians sampel homogen, maka pengujian hipotesis dengan menggunakan ANOVA dapat dilakukan. Analisis terhadap data hasil belajar bahasa indonesia dilakukan dengan menggunakan ANOVA dua arah yang proses perhitungannya dibantu dengan program SPSS 15.0 for Windows. Hasil uji ANOVA tersebut kemudian dilanjutkan dengan uji $t$ untuk mengetahui signifikansi perbedaan diantara masing-masing kelompok secara signifikan (simple effect). Dengan kata lain, uji $t$ digunakan dengan tujuan untuk melihat kelompok sampel mana yang lebih tinggi hasil belajar bahasa Indonesianya ditinjau dari metode pembelajaran dan media pembelajaran. Adapun ringkasan hasil analisis data dengan menggunakan ANOVA dapat dilihat pada tabel berikut ini.

Tabel 1.

Ringkasan Hasil ANOVA

Tests of Between-Subjects Effects

Dependent Variable: NILAI

\begin{tabular}{|l|r|r|r|r|r|}
\hline Source & \multicolumn{1}{|c|}{$\begin{array}{c}\text { Type III Sum } \\
\text { of Squares }\end{array}$} & df & Mean Square & \multicolumn{1}{c|}{ F } & \multicolumn{1}{c|}{ Sig. } \\
\hline Corrected Model & $3616,500(a)$ & 3 & 1205,500 & 29,749 &, 000 \\
Intercept & 497385,800 & 1 & 497385,800 & 12274,352 &, 000 \\
METODE & 1201,250 & 1 & 1201,250 & 29,644 &, 000 \\
MEDIA & 2184,050 & 1 & 2184,050 & 53,897 &, 000 \\
METODE & 231,200 & 1 & 231,200 & 5,705 &, 019 \\
MEDIA & 3079,700 & 76 & 40,522 & & \\
Error & 504082,000 & 80 & & & \\
Total & 6696,200 & 79 & & & \\
Corrected Total & & & & \\
\hline
\end{tabular}

a R Squared $=, 540$ (Adjusted R Squared $=, 522$ )

Berdasarkan table uji ANOVA tersebut maka dapat dianalisis hasil pengujian hipotesis sebagai berikut: $\begin{array}{llr}\text { 1. Hipotesis Pertama: } & \begin{array}{r}\text { Terdapat } \\ \text { Pengaruh } \\ \text { Petode }\end{array}\end{array}$ 
Terhadap Hasil Belajar Bahasa Indonesia

Berdasarkan tabel 4.21 baris 3 mengenai ringkasan hasil ANOVA (output SPSS) terlihat bahwa sign. untuk metode pengajaran (MP) sebesar 0,000. Dengan demikian maka nilai tersebut lebih kecil dari $0,05(0,000<0,05)$. Berdasarkan hal tersebut maka hipotesis nol $\left(H_{0}\right)$ ditolak dan hipotesis alternatif $\left(H_{1}\right)$ diterima. Hal ini menunjukkan bahwa pengaruh rerata (mean) metode pengajaran dalam hal ini inquiri dan konventional adalah perbedaan yang signifikan. Dengan demikian maka dapat disimpulkan bahwa terdapat pengaruh metode pengajaran terhadap hasil belajar bahasa Indonesia siswa.

2. Hipotesis Kedua: Terdapat Pengaruh Media Pembelajaran Terhadap Hasil Belajar Bahasa Indonesia

Berdasarkan tabel 4.21 baris 4 mengenai ringkasan hasil ANOVA (output SPSS) terlihat bahwa sign. untuk media pembelajaran (MM) siswa sebesar 0,000. Dengan demikian maka nila sign. tersebut lebih kecil dari 0,05 $(0,000<0,05)$. Berdasarkan hal tersebut maka hipotesis nol $\left(H_{0}\right)$ ditolak dan hipotesis alternatif $\left(H_{1}\right)$ diterima. Hal ini menunjukkan bahwa perbedaan rerata (mean) responden yang diajar dengan menggunakan media audio visual dengan siswa yang diajar tanpa menggunakan media audio visual adalah perbedaan yang signifikan. Dengan demikian maka dapat disimpulkan bahwa terdapat pengaruh media pembelajaran terhadap hasil belajar bahasa indonesia siswa.

3. Hipotesis Ketiga : Terdapat Pengaruh Interaksi Metode dan Media Pembelajaran Terhadap Hasil Belajar Bahasa Indonesia.
Berdasarkan tabel 4.21 baris 5 (lima) mengenai ringkasan hasil ANOVA (output SPSS) terlihat bahwa nilai sign. untuk interaksi (MP*MM) sebesar 0,019. Nilai sign tersebut lebih kecil dari 0,05 (0,019 $<0,05)$ maka, maka hipotesis nol $\left(\mathrm{H}_{0}\right)$ ditolak dan hipotesis alternatif $\left(H_{1}\right)$ diterima. Hal ini membuktikan bahwa terdapat pengaruh interaksi antara metode pengajaran dan media pembelajaran terhadap hasil belajar bahasa indonesia siswa secara signifikan. Dengan demikian maka dapat disimpulkan bahwa terdapat pengaruh interaksi antara metode pengajaran dan media pembelajaran terhadap hasil belajar bahasa indonesia.

Karena terdapat pengaruh interaktif, maka hipotesis dalam penelitian ini dilanjutkan dengan pengujian simple effect yaitu dengan menggunakan uji Tukey. Hasil perhitungan uji Tukey dapat dilihat pada tabel berikut ini:

Tabel 2

Post Hoc Uji Lanjut Dengan Uji Tukey

\begin{tabular}{|c|c|c|c|c|c|}
\hline \multirow{6}{*}{$\begin{array}{l}\text { (I)Ke } \\
\text { lomp } \\
\text { ok } \\
\text { (J)Ke } \\
\text { lomp } \\
\text { ok }\end{array}$} & \multirow[t]{6}{*}{$\begin{array}{c}\text { Mea } \\
\mathrm{n} \\
\text { Diffe } \\
\text { rence } \\
(\mathrm{I}-\mathrm{J})\end{array}$} & \multirow[t]{6}{*}{$\begin{array}{c}\text { Std. } \\
\text { Err } \\
\text { or }\end{array}$} & \multirow[t]{6}{*}{$\begin{array}{l}\mathrm{S} \\
\mathrm{i} \\
\mathrm{g} .\end{array}$} & \multicolumn{2}{|c|}{$\begin{array}{c}95 \% \\
\text { Confiden } \\
\text { ce } \\
\text { Interval }\end{array}$} \\
\hline & & & & Lo & Up \\
\hline & & & & we & per \\
\hline & & & & $\mathrm{r}$ & Bo \\
\hline & & & & Bo & un \\
\hline & & & & $\begin{array}{c}\text { un } \\
\text { d }\end{array}$ & $\mathrm{d}$ \\
\hline \multirow[t]{9}{*}{1} & 4,35 & 2,0 &, 1 & - & 9,6 \\
\hline & 00 & 130 & 4 & ,93 & 37 \\
\hline & 7,05 & 2 & 4 & 78 & 8 \\
\hline & $00(*)$ & 2,0 & , 0 & 1,7 & 12 , \\
\hline & 18,2 & 130 & 0 & 62 & 33 \\
\hline & 000( & 2 & 4 & 2 & 78 \\
\hline & *) & 2,0 & ,0 & 12 , & 23 , \\
\hline & & 130 & 0 & 91 & 48 \\
\hline & & 2 & 0 & 22 & 78 \\
\hline \multirow[t]{3}{*}{2.} & - & 2,0 &, 1 & & ,93 \\
\hline & 4,35 & 130 & 4 & 9,6 & 78 \\
\hline & 00 & 2 & 4 & 37 & 7,9 \\
\hline \multirow[t]{2}{*}{ 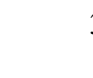 } & 2,70 & 2,0 &, 5 & 8 & 87 \\
\hline & 00 & 130 & 4 & - & 8 \\
\hline & & 2 & 0 & 2,5 & \\
\hline
\end{tabular}




\begin{tabular}{|c|c|c|c|c|c|}
\hline & 13,1 & 2,0 & 0 & 87 & 19, \\
\hline & 8500 & 130 & 0 & 8 & 13 \\
\hline & $(*)$ & 2 & 0 & 8,5 & 78 \\
\hline & & & & 62 & \\
\hline & & & & 2 & \\
\hline 3. & - & 2,0 & , 0 & - & - \\
\hline & 7,05 & 130 & 0 & 12 , & 1,7 \\
\hline & $00\left(^{*}\right)$ & 2 & 4 & 33 & 62 \\
\hline 2 & - & 2,0 & ,5 & 78 & 2 \\
\hline & 2,70 & 130 & 4 & - & 2,5 \\
\hline 4 & 00 & 2 & 0 & 7,9 & 87 \\
\hline & 11,1 & 2,0 & ,0 & 87 & 8 \\
\hline & 500 & 130 & 0 & 8 & 16, \\
\hline & $*)$ & 2 & 0 & 5,8 & 43 \\
\hline & & & & 62 & 78 \\
\hline & & & & 2 & \\
\hline 4. & - & 2,0 & 0 & - & - \\
\hline & 18,2 & 130 & 0 & 23 , & 12 , \\
\hline & 000 & 2 & 0 & 48 & 91 \\
\hline & $*)$ & 2,0 & ,0 & 78 & 22 \\
\hline & - & 130 & 0 & - & - \\
\hline & 13,8 & 2 & 0 & 19 , & 8,5 \\
\hline & 500( & 2,0 & ,0 & 13 & 62 \\
\hline & $*)$ & 130 & 0 & 78 & 2 \\
\hline & - & 2 & 0 & - & - \\
\hline & 11,1 & & & 16 , & 5,8 \\
\hline & 500( & & & 43 & 62 \\
\hline & $*)$ & & & 78 & 2 \\
\hline
\end{tabular}

* the mean different is significant at the 0.05 level.

Dari tabel di atas dapat disimpulkan sebagai berikut:

a. Pada kelompok 1 dan kelompok 2 terlihat bahwa mean difference sebesar $(0,435)$ artinya selisih antara rata-rata hasil belajar bahasa Indonesia kelompok 1 dan 2 sebesar $(0,435)$. Nilai ini cukup kecil dan dapat dibuktikan dengan nilai sig. $0,14>0,05$ atau dapat diartikan bahwa kelompok 1 dan 2 tidak berbeda secara signifikan.

b. Pada kelompok 1 dan 3 terlihat bahwa mean difference sebesar 7,05 , artinya selisih rata-rata hasil belajar bahasa Indonesia antara kelompok 1 dan 3 cukup besar dan dapat dibuktikan dengan nilai sig. $0,004<0,05$ atau dapat diartikan bahwa kelompok 1 dan 3 berbeda secara signifikan. c. Pada kelompok 2 dan 4 terlihat bahwa mean difference sebesar 13,85 , artinya selisih rata-rata hasil belajar bahasa Indonesia antara kelompok 2 dan 4 cukup besar dan dapat dibuktikan dengan nilai sig. $0,000<0,05$ atau dapat atau dapat diartikan bahwa kelompok 2 dan 4 berbeda secara signifikan.

d. Pada kelompok 3 dan 4 terlihat bahwa mean difference sebesar 11,15 , artinya selisih rata-rata hasil belajar bahasa Indonesia antara kelompok 3 dan 4 cukup besar dan dapat dibuktikan dengan nilai sig. $0,000<0,05$ atau dapat diartikan bahwa kelompok 3 dan 4 berbeda secara signifikan.

\section{PEMBAHASAN}

Untuk menjawab apakah terdapat pengaruh metode pengajaran terhadap hasil belajar bahasa Indonesia diperoleh hasil bahwa metode pengajaran dan hasil belajar bahasa indonesia terdapat pengaruh yang signifikan. Berdasarkan tabel 4.21 baris 3 mengenai ringkasan hasil ANOVA (output SPSS) terlihat bahwa sign. untuk metode pengajaran (MP) sebesar 0,000. Dengan demikian maka nilai tersebut lebih kecil dari 0,05 $(0,000<0,05)$. Berdasarkan hal tersebut maka hipotesis nol $\left(H_{0}\right)$ ditolak dan hipotesis alternatif $\left(H_{1}\right)$ diterima. Hal ini menunjukkan bahwa pengaruh rerata (mean) metode pengajaran dalam hal ini metode pembelajaran inkuiri dan konvensional adalah perbedaan yang signifikan. Dengan demikian maka dapat disimpulkan bahwa terdapat pengaruh metode pembelajaran inkuiri terhadap hasil belajar bahasa Indonesia siswa.

Berdasarkan tabel 1 baris 4 mengenai ringkasan hasil ANOVA (output SPSS) terlihat bahwa sign. untuk media pembelajaran (MM) siswa sebesar 
0,000. Dengan demikian maka nila sign. tersebut lebih kecil dari 0,05 $(0,000<$ $0,05)$. Berdasarkan hal tersebut maka hipotesis nol $\left(H_{0}\right)$ ditolak dan hipotesis alternatif $\left(H_{1}\right)$ diterima. Hal ini menunjukkan bahwa perbedaan rerata (mean) responden yang diajar dengan menggunakan media audio visual dan tanpa menggunakan media pembelajaran audio visual adalah perbedaan yang signifikan. Dengan demikian maka dapat disimpulkan bahwa terdapat pengaruh yang signifikan media pembelajaran audio visual terhadap hasil belajar bahasa Indonesia siswa.

Berdasarkan tabel 1 baris 5 (lima) mengenai ringkasan hasil ANOVA (output SPSS) terlihat bahwa nilai sign. untuk interaksi (MP*MM) sebesar 0,019 . Nilai sign tersebut lebih kecil dari $0,05(0,019<0,05)$ maka, maka hipotesis nol $\left(H_{0}\right)$ ditolak dan hipotesis alternatif $\left(H_{1}\right)$ diterima. Hal ini membuktikan bahwa terdapat pengaruh interaksi yang signifikan antara metode dan media pembelajaran terhadap hasil belajar bahasa Indonesia. Dengan demikian maka dapat disimpulkan bahwa terdapat pengaruh interaksi yang signifikan metode dan media pembelajaran terhadap hasil belajar bahasa Indonesia siswa.

\section{SIMPULAN}

Berdasarkan dari hasil pengujian hipotesis penelitian dan analisis pengolahan data pada bab IV, maka dapat disimpulkan sebagai berikut :

1. Terdapat pengaruh yang signifikan metode pembelajaran terhadap hasil belajar bahasa Indonesia. Hal tersebut dibuktikan dengan $F_{h}$ 29.644 dan sig. sebesar $0,000<$ 0,05 , yang membuktikan bahwa perbedaan rerata (mean) nilai siswa yang diajar dengan metode pengajaran inquiri dan konvensional adalah perbedaan yang signifikan.

2. Terdapat pengaruh yang signifikan media pembelajaran terhadap hasil belajar bahasa Indonesia. Hal tersebut dibuktikan dengan $F_{h}$ 53.897 dan sig. $0,000<0,05$, yang membuktikan bahwa perbedaan rerata (mean) nilai siswa yang diajar dengan media audio visual dan tanpa media audio visual adalah perbedaan yang signifikan.

3. Terdapat pengaruh interaktif yang signifikan metode dan media pembelajaran terhadap hasil belajar bahasa Indonesia. Hal tersebut dibuktikan dengan $F_{h} 5.705$ dan sig. $0,019<0,05$, yang berarti terdapat pengaruh interakif metode pengajaran dan media pembelajaran terhadap hasil belajar bahasa Indonesia. Berdasarkan pengujian simple effect dengan menggunakan hasil uji Tukey menyimpulkan:

a. Tidak terdapat perbedaan yang signifikan antara hasil belajar kelompok siswa yang menggunakan metode dan media pembelajaran dan kelompok siswa yang hanya menggunakan metode pembelajaran. Hal ini dibuktikan dengan mean difference sebesar 0,43 nilai sig. $0,14>0,05$.

b. Terdapat perbedaan yang signifikan hasil belajar bahasa Indonesia pada kelompok siswa yang diajar dengan menggunakan metode dan media pembelajaran dan kelompok hasil belajar siswa yang diajar dengan menggunakan media pembelajaran saja. Hal ini dituntukkan dengan mean difference sebesar 7,05 dan nilai sig. $0,004<0,05$. 
c. Terdapat perbedaan yang signifikan hasil belajar bahasa Indonesia pada kelompok siswa yang belajar menggunakan metode pembelajaran dan kelompok siswa yang tidak menggunakan metode dan media pembelajaran. Hal ini dapat dibuktikan dengan mean difference sebesar 13,85 dan nilai sig. $0.00<0,05$.

d. Terdapat perbedaan yang signifikan hasil belajar bahasa Indonesia kelompok siswa yang hanya menggunakan metode pembelajaran dan kelompok siswa yang tidak menggunakan metode dan media pembelajaran. Hal ini ditunjukkan dengan mean difference sebesar 11,15 dan nilai sig $0,00<0,05$.

Berdasarkan simpulan dan implikasi penelitian, maka beberapa saran terkait yang dapat penuli sampaikan pada penelitian ini adalah :

1. Metode pembelajaran inkuiri dapat diterapkan dalam berbagai model pembelajaran yang, oleh karena itu guru hendaknya memperbanyak pengetahuan teori dan strategi melalui metode pembelajaran inkuiri melalui metode menyenangkan dan variatif.

2. Diperlukan media pembelajaran supaya proses pembelajaran menyenangkan dan siswa dapat dengan mudah menyerap pesan pembelajaran yang dikomunikasikan guru kepada mereka. Hal ini akan menunjang keberhasilan pembelajaran yang maksimal.

3. Guru hendaknya menggunakan berbagai metode dan media pembelajaran agar siswa dapat mencapai tujuan pembelajaran dengan maksimal. Pemilihan metode dan media pembelajaran hendaknya disesuaikan dengan kebutuhan siswa agar penggunaan metode dan media pembelajaran memberikan pengaruh yang positif terhadap hasil pembelajaran siswa.

\section{DAFTAR PUSTAKA}

Arifin, Z. (2012). Model-Model Pembelajaran Berbasis Paikem. Tangerang: PustakaMandiri.

Arsyad, A. (2015). Media Pembelajaran. Jakarta: Grafindo

Dimyati, M. (2012). Belajar dan Pembelajaran. Jakarta: Rineka Cipta.

Hamid, S. (2011). Metode Edutainment. Jogjakarta: Diva Press.

Supardi. (2013). Aplikasi Statistik Dalam Penelitian Edisi Revisi. Jakarta: Smart Prima Ufuk Semesta.

Susanto, A. (2013). Teori Belajar dan Pembelajaran di Sekolah. Jakarta: Prenada Media Grup. 